\title{
Island-generated internal waves at Scott Reef,
}

\section{Western Australia}

\section{Eric Wolanski ${ }^{\mathrm{a}, *}$, Eric Deleersnijder ${ }^{\mathrm{b}}$}

aAstralian Institute of Marine Science, PMB No. 3Mc, Townsville M.C., Queensland 4810, Australia

${ }^{\circ} G$. Lemaitre Institute of Astronomy and Geophysics, Catholic University of Louvain, Chemin du Cyclotron 2, B-1348 Louvain-La-Neuve, Belgium

Received 7 April 1998; accepted 18 May 1998

\section{Abstract}

Oceanographic field studies were carried out, in August-October 1993, of the water circulation around Scott Reef, a $39 \mathrm{~km}$ wide island rising nearly vertically in $500 \mathrm{~m}$ depth on the outer continental shelf slope of Western Australia. Macro-tide prevailed and generated $0.6 \mathrm{~m}$ $\mathrm{s}^{-1}$ tidal currents. Internal waves $60 \mathrm{~m}$ peak-to-trough occurred around Scott Reef mainly at the semi-diurnal frequencies. A numerical model and the field data suggested that the internal waves were locally generated by the interaction of the tidal currents and the bathymetry. Also these waves were predicted to rotate counterclockwise around the island with maximum amplitude along the island slopes, while radiating energy as free internal waves propagating freely away in the open ocean. They were generated apparently without eddies forming in the freely away in the open ocean. They were generated apparently without eddies forming in the
lee of the island. The wave frequencies were not restricted to the diurnal and semi-diurnal tidal frequencies which dominated the sea surface fluctuations, indeed higher frequencies were important. The energy at the inertial frequency was negligible. It appears that oceanic islands are internal wave generators and may contribute to the oceanic variability even far away. (C) 1998 Elsevier Science Ltd. All rights reserved

\section{Introduction}

Since surface waters of the oceans are generally oligotrophic, it is believed that oceanographic processes occur around islands to make these systems productive and sustain coral reefs and commercially important fisheries. There may be several oceanographic processes by which nutrient enrichment occurs, including isotherm doming in island wakes, internal waves, boundary mixing and geo-thermal

*Corresponding author. E-mail: ericw@ibm590.aims.gov.au.

0278-4343/98/\$ - See front matter (C) 1998 Elsevier Science Ltd. All rights reserved PII: S0278-4343(98)00069-7 
endo-upwelling (Hogg, 1972; Gordon and Hughes, 1981; Simpson et al., 1982; Simpson and Tett, 1986; Wolanski, 1986; Heywood et al., 1990; Frank, 1992; Rougerie et al., 1992; Wolanski and Delesalle, 1995). The supporting field evidence is sparse. Nutrient enrichment by island wakes and boundary mixing appears unlikely to be important for oceanic atolls because the enrichment occurs at the unlikely to be pycnocline, typically $100 \mathrm{~m}$ below the surface which is too deep to influence the near-surface corals and fisheries. The internal waves appear a more likely candidate. Field studies of internal waves have generally focused on processes on a smooth continental slope (Huthnance, 1989; Holloway and Barnes, 1998). rare, exceptions dealing with a more complex toporaph including There are a few, and islands. These studies were largely numerical and complemented by sparse field data and hydraulics experiments. They suggested that the internal waves are greatly amplified by a rugged topography. (Maxworthy, 1979; Gordon and Hughes, 1981. Baines, 1983; Crepon et al., 1984; De Young and Pond, 1987; Di Sarra et al., 1987; Wilmont and Edwards, 1987; Wolanski et al., 1988; Le Tareau and Maze, 1993; Bowman et al., 1994; Lamb, 1994; Morozov and Vlasenko, 1996).

For the case of oceanic islands these studies have focused mostly on the isotherm doming downstream of the island in an eddy or bubble in a steady flow, it was generally assumed that the isotherm doming was island trapped. The supporting field data suggested very large ( $\approx 100 \mathrm{~m}$ peak to trough) semidiurnal internal waves near some islands such as Myrmidon Reef on the Great Barrier Reef (Wolanski, 1986), Tahiti in French Polynesia (Wolanski and Delesalle, 1995) and Mururoa Atoll also in French Polynesia (Garrigues et al., 1993). These data however were sparse, taken only at one side of the island and no data were available on the three-dimensiona dynamics of these internal waves.

To better understand these island-generated internal waves we undertook a field experiment at Scott Reef $\left(121^{\circ} 50^{\prime} \mathrm{E}, 14^{\circ} \mathrm{S}\right.$; Fig. 1), a $39 \mathrm{~km}$ wide island in about $500 \mathrm{~m}$ water depth on the continental slope of the north west shelf of Australia. This island is very remote and was only accessible twice, while deploying and recovering oceanographic moorings. We deployed moorings on opposite sides of the island. We found $60 \mathrm{~m}$ high internal waves that occurred at a number of frequencies including tida frequencies and higher frequencies not present in the sea level dat. semi-diurnal internal waves did appear to be about out-of-phase on opposite sides of the island. We modelled these waves with a two-layer representation and the model predicted that the semi-diurnal waves were indeed out-of-phase on opposite sides of the island. The model suggested the waves were rotating counterclockwise opite sides of the island. The model suggested the waves were rotating counterclockwise around the island with maximum amplitude on the island slope while radiating energy as free internal waves propagating freely away in the open ocean. These internal waves were generated in the absence of eddies in the lee of the island.

\section{Methods}

In August-October 1993, Inter-Ocean model S4 current meters were deployed at sites A1, A2 and B2 on the slopes of Scott Reef (Fig. 1). These sites were located
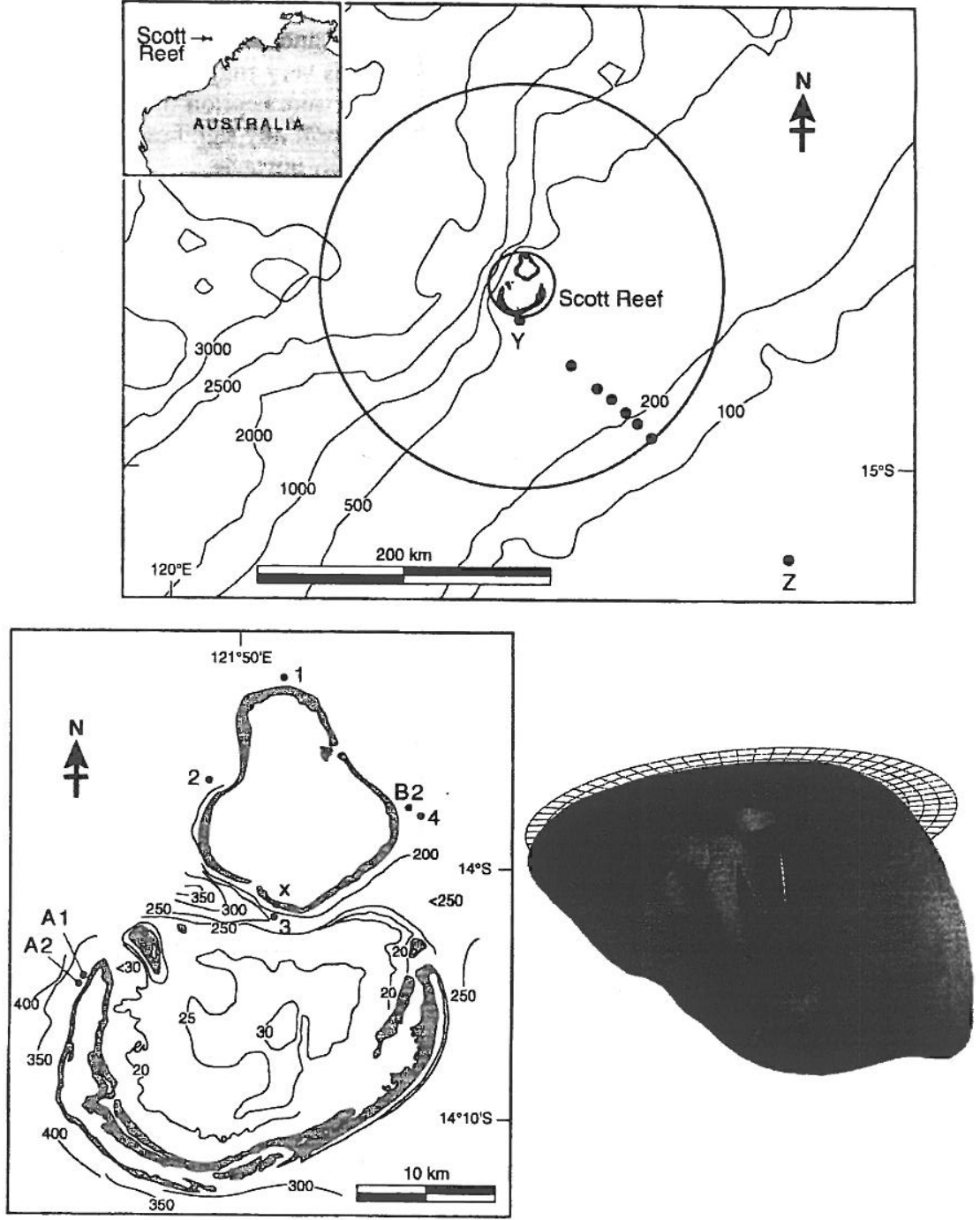

Fig. 1. Location map of Scott Reef on the slope of the Australian North-West continental shelf. The near-field bathymetric chart shows depth in fathoms ( 1 fathom $=1.8 \mathrm{~m}$ ), the mooring sites ( $\mathrm{A1}, \mathrm{A2}, \mathrm{B2}, \mathrm{X})$
and the CTD sites $1-4$ in the October 1993 cruise. The large-scale map and the three-dimensional rendering of the far-field topography viewed from the north-north-east show depth in $\mathrm{m}$, the circular rol ren and the grid resolution, as well as the location of the CTD stations during the transect from Scott Ref towards the coast in October 19-20, 1993. 
respectively, in about 100,200 and $200 \mathrm{~m}$ of water. The meters were located $46 \mathrm{~m}$ of the bottom at site A1 and $26 \mathrm{~m}$ off the bottom at site A2 and B2. The meters logged every $10 \mathrm{~min}$ data averaged over $1 \mathrm{~min}$. The bottom was very rugged and the exact depth was unknown to within $10 \mathrm{~m}$. The current meters were kept off the bottom by a subsurface buoy with a lift of $120 \mathrm{~kg}$, sufficient to prevent kept off the bottom by knockdown. The meters did not record pressure or depth however.

An Aanderaa tide gauge was bottom-mounted by divers in about $20 \mathrm{~m}$ depth at site $X$. This meter logged data every $30 \mathrm{~min}$ averaged over $1 \mathrm{~min}$.

Daily wind data, reconstructed from shore-based observations, were obtained from the Bureau of Meteorology.

CTD data were obtained during the mooring deployment and recovery $300 \mathrm{~m}$.

\section{Results}

The waters were stratified in temperature and salinity (Fig. 2). The surface, wellmixed layer was about $100 \mathrm{~m}$ thick in August and $80 \mathrm{~m}$ thick in October. There was a weak salinity maximum at 100-200 m depth. The density gradient in the upper $300 \mathrm{~m}$ was mostly controlled by the temperature. The CTD casts (Fig. 3)

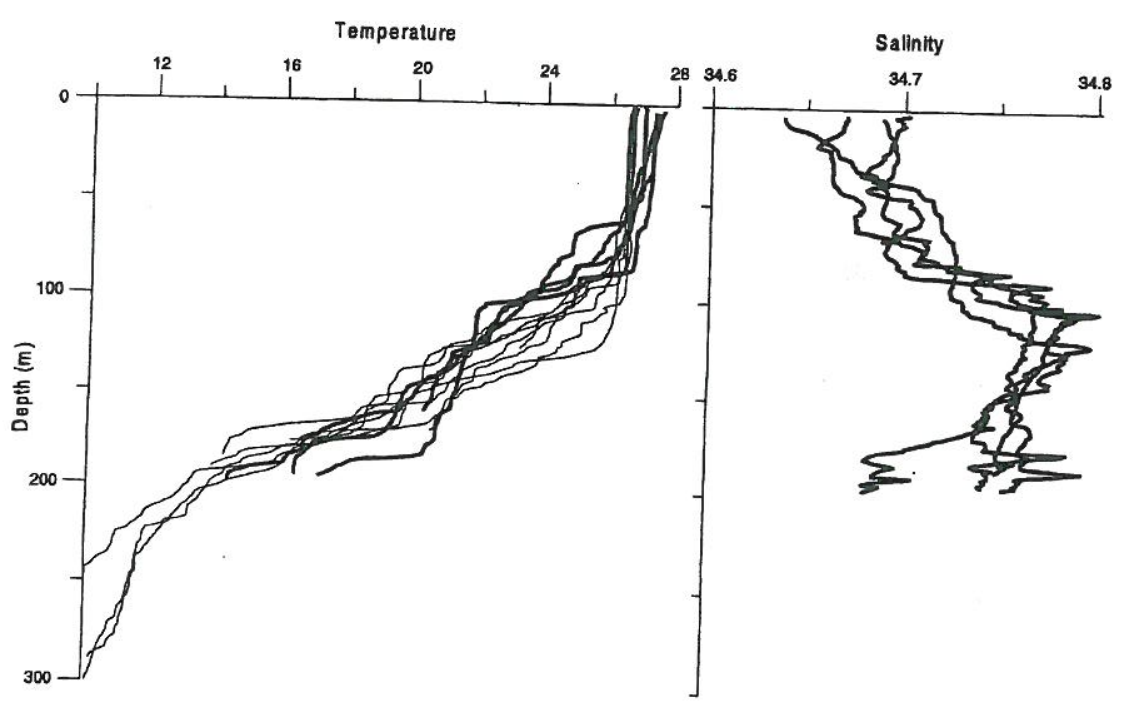
Fig. 2. Vertical profiles of temperature and salinity at stations within $5 \mathrm{~km}$ around Scott Reef during the
August 1993 (thin lines) and October 1993 (thick lines) cruises.

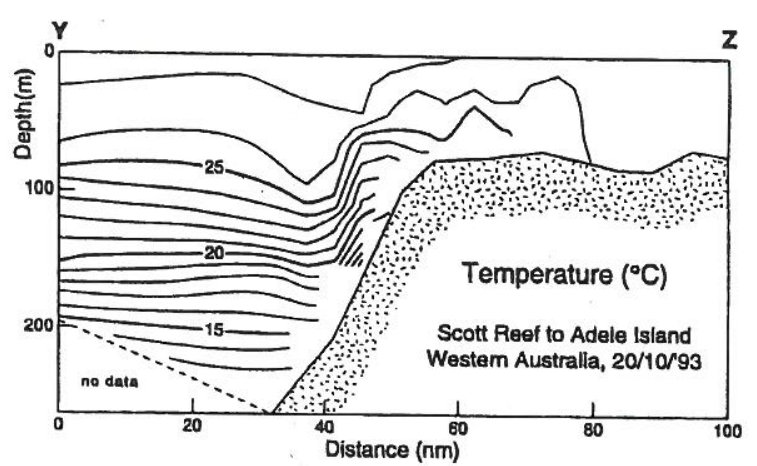

Fig. 3. Distribution of temperature along a transect from Scott Reef (left) to Adele Island on the continental shelf on October 19-20, 1993. The location of the stations is shown in Fig. 1. Except on the upper continental slope and on the shelf itself, the profiles did not extend all the way to the bottom in order to save time during the cruise. The data is not synoptic because the survey lasted two days. The contouring package preserved vertical oscillations $>1 \mathrm{~m}$, hence the plot was not artificially smoothed. While we did not find in this survey an island-generated internal wave, we clearly measured an internal wave spilling over the shelf, a common feature on the north-west shelf of Australia $500 \mathrm{~km}$ to the southwest (Holloway, 1996). No data are available on the internal wave at the shelf edge near this area.

show negligible horizontal gradients near Scott Reef at that time. These horizontal gradients were large only at the edge of the continental shelf.

The Brunt-Vaisala period at $150 \mathrm{~m}$ depth where the vertical gradient of density was the largest and calculated from the mean of the density profiles shown in Fig. 2, was about 0.0069 days. There is no unique internal mode in the ocean around Scott Reef because the depth varies from 4000 to $100 \mathrm{~m}$ at the edge of the continental shelf. The inertial period is 2.03 days.

Semi-diurnal tides prevailed, with a spring tide of $4 \mathrm{~m}$ and a neap tide of $1 \mathrm{~m}$ (Fig. 4) These tides generated strong reversing tidal currents peaking at about $0.7 \mathrm{~m} \mathrm{~s}^{-1}$ and associated temperature fluctuations peaking at $11^{\circ} \mathrm{C}$ (Fig. 4). These currents and temperature fiuctuations also showed a marked spring-neap tide cycle related to the surface tide. Indeed the temperature fluctuations were less than $2^{\circ} \mathrm{C}$ at neap tides when the seal level fluctuations were about $1 \mathrm{~m}$, as opposed to typically 8 to $9^{\circ} \mathrm{C}$ at spring tides. In the absence of marked horizontal gradients in temperature near Scott Reef, these temporal changes of the temperature can be attributed to vertical displacements of isotherms, ie. internal waves. There were also low-frequency fluctuations these may be surprisingly were only marginally correlated at site A2 and B2 (not shown).

The strongest signal for currents and temperature was at semi-diurnal frequencies and occurred at spring tides. Two examples are shown in Figs. 5 and 6 . A comparison of the temperature time series with the vertical profiles of temperature (Fig. 2) suggests an internal wave of $60 \mathrm{~m}$ peak-to-trough. At these times the temperature fluctuations at sites A2 and B2 were composed of semi-diurnal fluctuations and of higher-frequency 


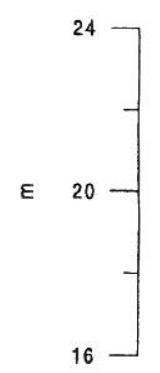

Sea Level

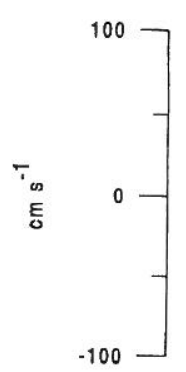
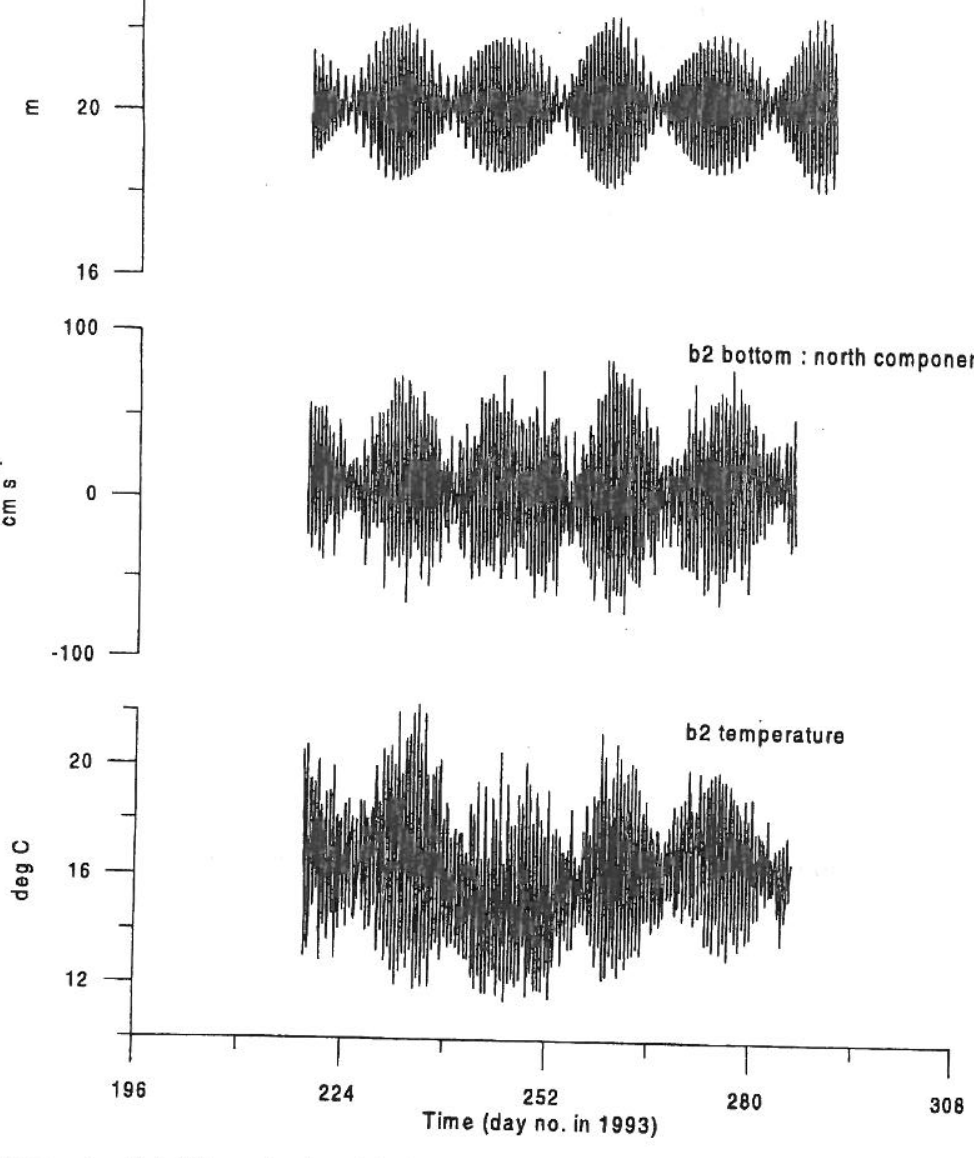
Fig. 4 . Time series plot of the sea level and the longshore current (positive if northward) and temperature at
site B2 (bottom).

motions. The semi-diurnal fluctuations at sites A2 and B2 were out-of-phase, high temperature at sites $\mathrm{A} 2$ occurring during low temperature at sites $\mathrm{B} 2$ and vice versa. This finding suggests the presence of an internal wave essentially out-of-phase on opposite sides of the island. The currents were also frequently flowing in directions at opposite sides of the island (sites $A 2$ and $\mathrm{B2}$. Fig 5). The currents we topographically steered, parallel to the island slopes. The largest currents were observed at site B2 (bottom) and these peaked at $0.6 \mathrm{~m} \mathrm{~s}^{-1}$. Smaller currents prevailed
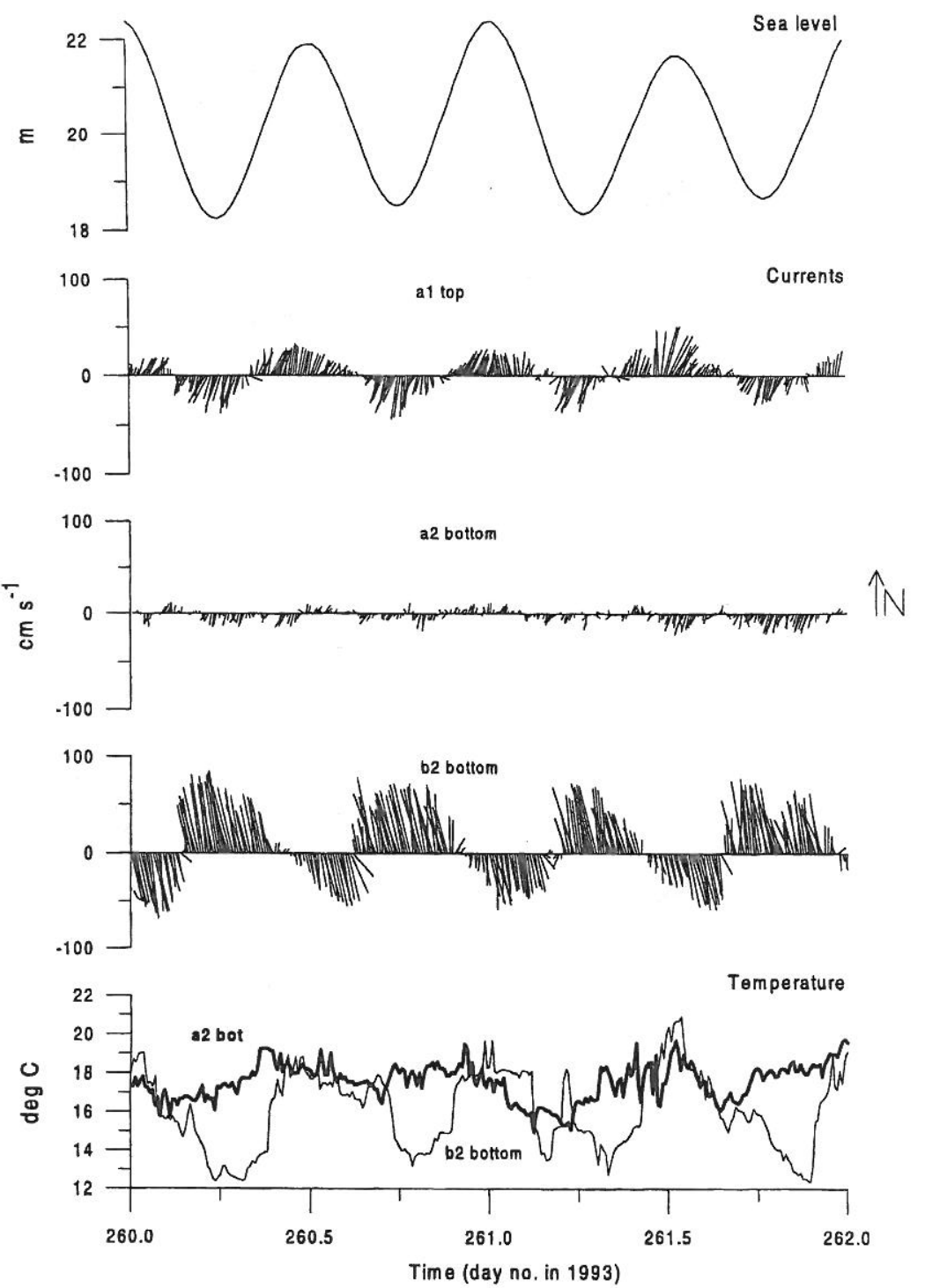

Fig. 5. This is a subsample of the data during spring tides and calm weather. Time series plot of the sea level at Scott Reef, stick plots of the currents at sites A1 (top), A2 (bottom), B2 (bottom) and the temperature at site A2 (bottom) and B2 (bottom) during days 260-262. 


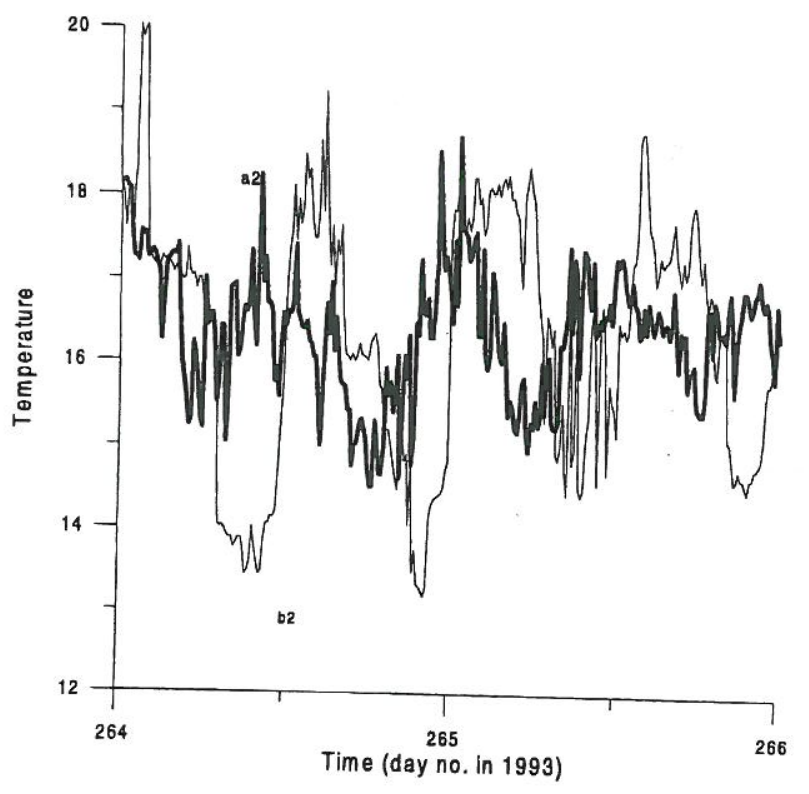

Fig. 6. Time series plot of the temperature at sites A2 (bottom) and B2 (bottom) during days 264-266.

at sites A2 (bottom) and A1 (top). The currents generally reversed direction at tida frequency, but at other times they did not (e.g. see in Fig. 5 the current vectors time series at site A2 around day 261.6 when the current changed direction for only 2 h) At that time a low-frequency southward current of about $0.17 \mathrm{~m} \mathrm{~s}^{-1}$ prevailed $2 \mathrm{~h}$ ). At (bottom), there was a zero net current at site A1 (top) and the current of $0.1 \mathrm{~m} \mathrm{~s}^{-1}$ at site B2 (bottom).

The spectrum of the sea level (Fig. 7) shows marked peaks at diurnal and semidiurnal tidal frequencies and negligible energy at higher harmonics. The inertial period ( 2.03 days) was largely absent from the spectrum of the sea level.

The low-frequency currents at all sites (not shown) reversed direction at periods of $5-20$ days, with peak currents seldom exceeding $0.15 \mathrm{~m} \mathrm{~s}^{-1}$, but they were incoherent from site to site. The spectra of the along-island currents (Fig. 7) showed marked peaks at the diurnal and semi-diurnal tidal frequencies. They also showed little marked at periods larger than the inertial one, a small but mea also showed little energy inertial frequency and a number of secondary diurnal and semi-diurnal ones. There than also measurable energy at frequencies larger than the semi-diurnal ones but none of these were tidal. Indeed a tidal harmonic analysis of these data (not shown) confirmed that these peaks cannot be accounted for by tides, e.g. the $\mathrm{M}_{4}$ component was largely absent. The bulk of the curcounted for occurred thus between the inertial and the Brunt-Vaisala frequencies, a finding suggesting they were generated by internal waves.

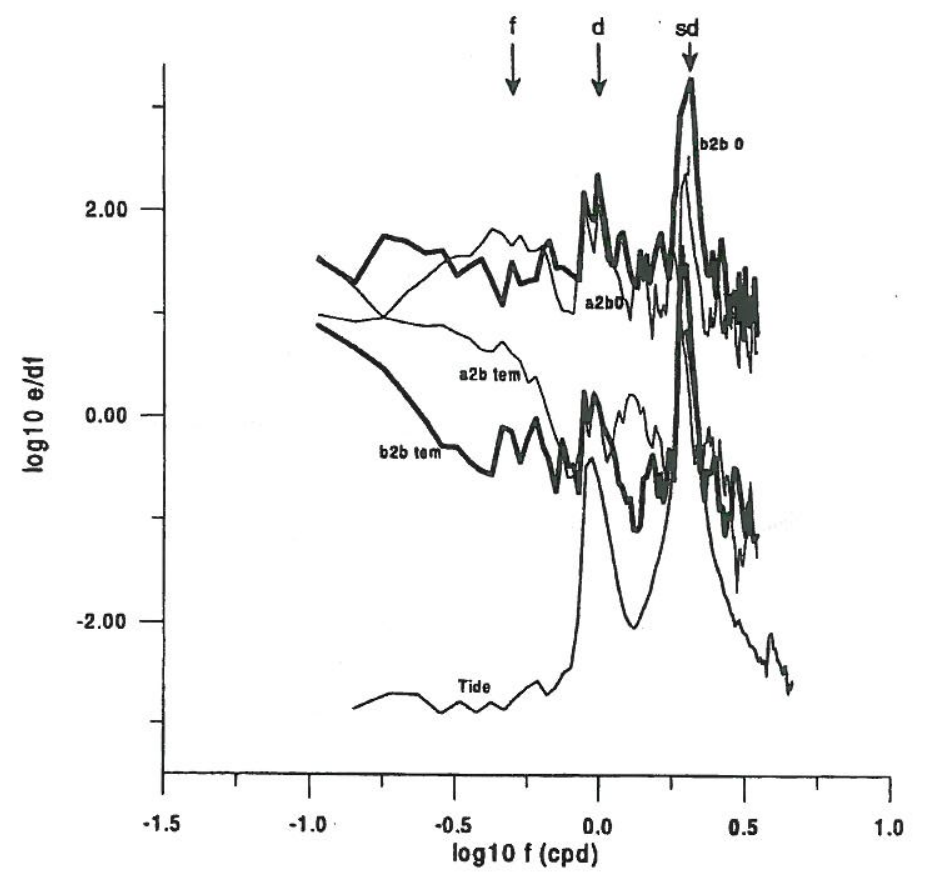

Fig. 7. Smoothened autospectrum of the sea level, longshore currents and temperature at sites A2 (bottom) and B2 (bottom) for August-October, 1993. The $95 \%$ confidence curves extend about $1 / 3$ of a decade at 1 day period. The peaks at the diurnal and semidiurnal frequencies are apparent. The intertial period is 2.03 cemi-diumal frequenciss semi-diumal frequencies. The maxinum Brunt-Vaisala period in the thermocline is 0.0069 days.

The temperature time series (e.g. Figs. 5 and 6 ) showed large, non-tidal fluctuations at high frequencies at site B2 (bottom) where the semi-diurnal fluctuations were also the largest. A smaller semi-diurnal fluctuation occurred at site A2 (bottom). At both sites there were high-frequency fluctuations, e.g. at site B2 (bottom) during days 265.5-266. At semi-diurnal frequency, there were many periods (nearly every low temperature event at site B2 in Fig. 4) when a low temperature occurred at site B2 (bottom) while at the same time a high temperature was found at site A2 (temperature), and vice versa. This finding suggests that the internal waves were out-of-phase on either sides of the island. The spectra of the temperature (Fig. 7) showed dominant peaks at the semi-diurnal and tidal frequencies. The spectra showed also a major second peak at 1.47 cycles per day at sites A2 (bottom) but not at site B2 (bottom). They were much more energetic at low frequencies at sites A2 (bottom) than at sites B2 (bottom). At both sides there was significant energy at non-tidal, high frequencies as well as at long periods greater than the inertial one. 


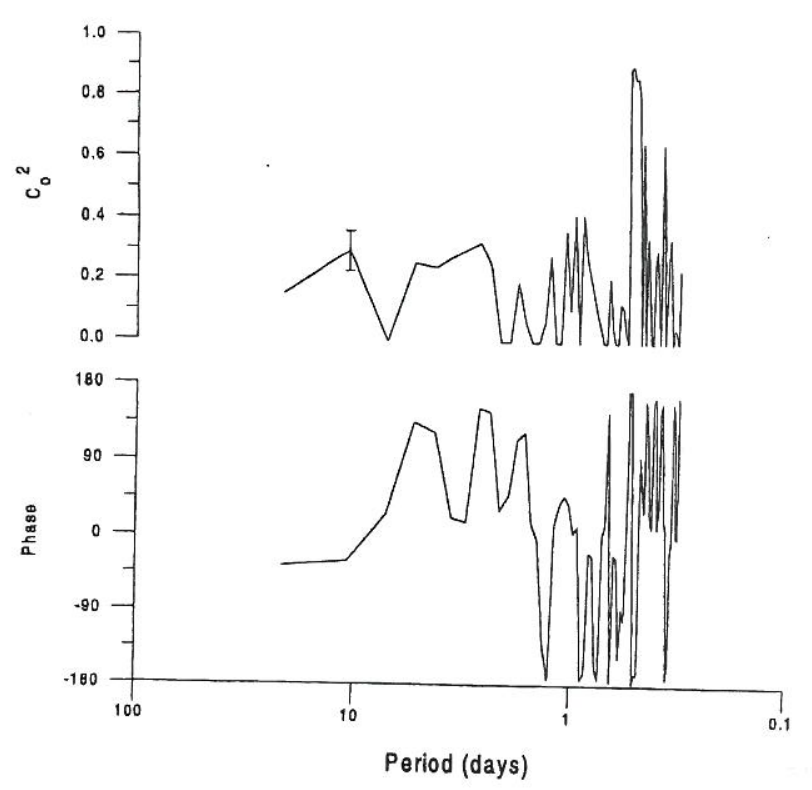

Fig. 8. Coherence squared $\left(c_{0}^{2}\right)$ and phase (in degrees) between the longshore currents and temperature at site $B 2$ (bottom). The bar represents the $95 \%$ confidence level at that period. At 1 day period the $95 \%$
confidence occurs at $C_{0}^{2} \simeq 0.9$.

The temperature and the dominant longshore currents (positive if northward) at site B2 (bottom) were significantly correlated $(R=-0.58)$. They were only marginally coherent $\left(c_{\mathrm{o}}^{2} \approx 0.5\right)$ at diurnal frequencies and highly coherent $\left(c_{\mathrm{o}}^{2} \approx 0.9\right)$ at the semidiurnal frequencies with a phase relationship of about $180^{\circ}$ (Fig. 8). The temperature time series at sites $\mathrm{A} 2$ and $\mathrm{B} 2$ were also correlated $(R=0.48)$. This correlation was largely due to a high coherence (Fig. 9$)$ at the diurnal $\left(c_{0}^{2} \approx 0.6\right)$ and semi-diurna $\left(c_{\mathrm{o}}^{2} \approx 0.9\right)$ frequencies. The phase at these periods varied typically between $110^{\circ}$ and $180^{\circ}$.

\section{Interpretation}

In this section, we infer from the data some properties of the internal waves at Scott Reef. Additional insight into these waves is gained with the help of a numerical model. Scott Reef is a coral atoll; the reefs emerge only at low tide. At high spring tide $(+4 \mathrm{~m})$ the water depth over the reef flat is $2-4 \mathrm{~m}$. This depth was too small to measurably affect the tidal currents at the moorin sites with $4 \mathrm{~m}$ tides prevailed and would be expected to dominate the dynam the temperature time series showed major fluctuations at different, non-tidal frequencies. The currents were often of opposite sign at opposite sides of the island at the same

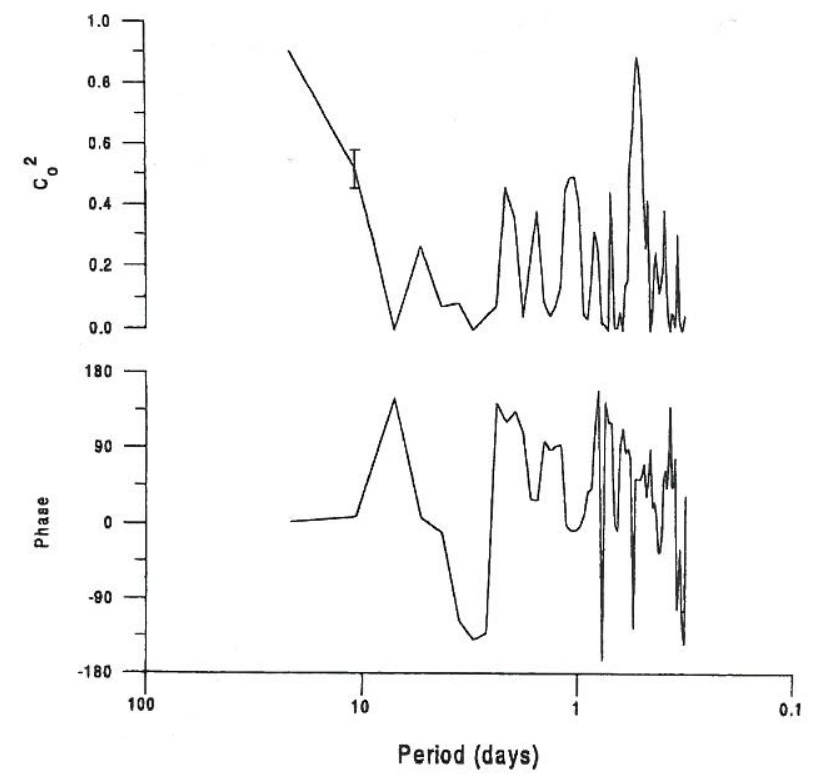

Fig. 9. Coherence squared $\left(c_{0}^{2}\right)$ and phase (in degrees) between the temperature at sites A2 (bottom) and B2 (bottom). The bar represents the $95 \%$ confidence level at the period.

depth (sites A2 and B2). There was considerable vertical shear of the currents exemplified by the occasional lag of up to $2 \mathrm{~h}$ between currents at the top (site A1) and at the bottom (site A2), these two sites were only $500 \mathrm{~m}$ apart. There were however long periods also when the currents at A1 (top) and A2 (bottom) were correlated and reversed with the tides at comparable times.

We focus our attention on the tidal forcing at diurnal and semi-diurnal frequencies because the energy of the sea level at these frequencies is typically a factor of 100 times larger than at other frequencies (Fig. 7). We argue that these observations are qualitatively consistent with what would occur in the presence of internal waves that were only present some of the time. In their absence the tidal currents at the top and bottom as well as on opposite sides of the island would be mostly reversing direction at tidal frequency and would be coherent at sites $\mathrm{A} 2$ and $\mathrm{B} 2$ (bottom). In the presence of these internal waves however, the currents can at times be oriented in opposite directions. The temperature time series revealed events of high and low temperature occurring at the same time on opposite sides of the island. At such times the internal wave was about out of phase on opposite sides of the island and was thus not a wave oscillating up and down uniformly all around the perimeter of the island. Such events appeared to occur preferentially at the semi-diurnal frequency. Occasionally, a wave crest was experienced at the same time on opposite sides of the island but at such times the internal wave at site A2 (bottom) appeared to oscillate at about twice the 
semi-diurnal tidal period. These observations suggest the presence of higher harmonic internal waves. At spring tides the observed wave was $60 \mathrm{~m}$ in height.

We argue that these waves are not due to free internal waves in the ocean and originating from somewhere else. Such highly energetic internal waves are rarely found in the open ocean. Further at Scott Reef the internal wave has a spring-neap cycle reproducing that of the surface tide, the semi-diurnal signal is the strongest in both surface and internal tides, and there exists a large phase difference, in some case approaching $180^{\circ} \mathrm{C}$, between the opposite sides of the islands. These findings strongly suggest that the internal waves are indeed island-generated.

From the data, it was unclear if the waves were of standing or propagating type. To solve this question we used a two-layer, non-linear model. Using a 3-D model would be much more difficult because many more variables would have to be prescribed and would be pointless because the far-field boundary conditions are ill-defined. A twolayer model is well-suited to schematically represent external waves and the first mode of internal waves, it is also best suited to test the interaction of a tidal current with island in a stratified ocean.

The two layer, non-linear model of Garrigues et al. (1993) was used. The model was written in polar coordinates. The island topography was simplified and assumed to be a cone rising from the ocean floor (Fig. 1). The slopes of this cone were vertical only in the top $120 \mathrm{~m}$ where the radius was $20 \mathrm{~km}$. Elsewhere the sea floor was not radially symmetric (Fig. 1) but was taken from the bathymetric charts. The outer radius of the model domain was $120 \mathrm{~km}$. As shown in Fig. 1, there were 33 grid points along a radial, unevenly spaced so that maximum resolution was achieved near the island. The angular resolution was $6^{\circ}$. The ocean was divided in two layers vertically, each of constant density. The surface layer was assumed to be $140 \mathrm{~m}$ thick at $26.5^{\circ} \mathrm{C}$ and the bottom layer was $18^{\circ} \mathrm{C}$. The salinity was uniform. No tangential stress was assumed to occur at the interface between the two layers. At the bottom, however, a friction stress was calculated with the help of the classical quadratic formula, involving the velocity in the bottom layer and a drag coefficient equal to 0.0025 . In each layer, a harmonic diffusion of momentum was present. The associated viscosity was $2.2 \times 10^{-8} \mathrm{~s}^{-1} \mathrm{x}$ (distance to the reef centre) ${ }^{2}$, implying that it ranged from about $9 \mathrm{~m}^{2} \mathrm{~s}^{-1}$ at the reef boundary to about $320 \mathrm{~m}^{2} \mathrm{~s}^{-1}$ at the open boundary of the computational the reef The model was forced by the surface tide along the outer radius of the mode with appropriate spatial lags so as to reproduce the tidal ellipses in the opent these were not measured and were taken from number these were not measured and were taken from numerical predictions of global ocean tides (Schwiderski, 1979). There was no explicit forcing of the internal wave at the outer radius of the model domain, the internal wave height was calculated instead by adding a sponge layer at the last three grid points all along the outer radius of model domain. The sponge absorbed all outgoing internal wave energy and numerical tests showed negligible internal wave reflection back into the model domain.

The model was initially run for a $2 \mathrm{~m}$ semi-diurnal tide and a flat sea bottom at $500 \mathrm{~m}$ depth. In such conditions an internal wave was predicted to form with maximum amplitude along the island slopes. The crests and troughs occurred at opposite sides (Fig. 10), and this prediction was in qualitative agreement with the observations that at times low and high temperatures occurred simultaneously at
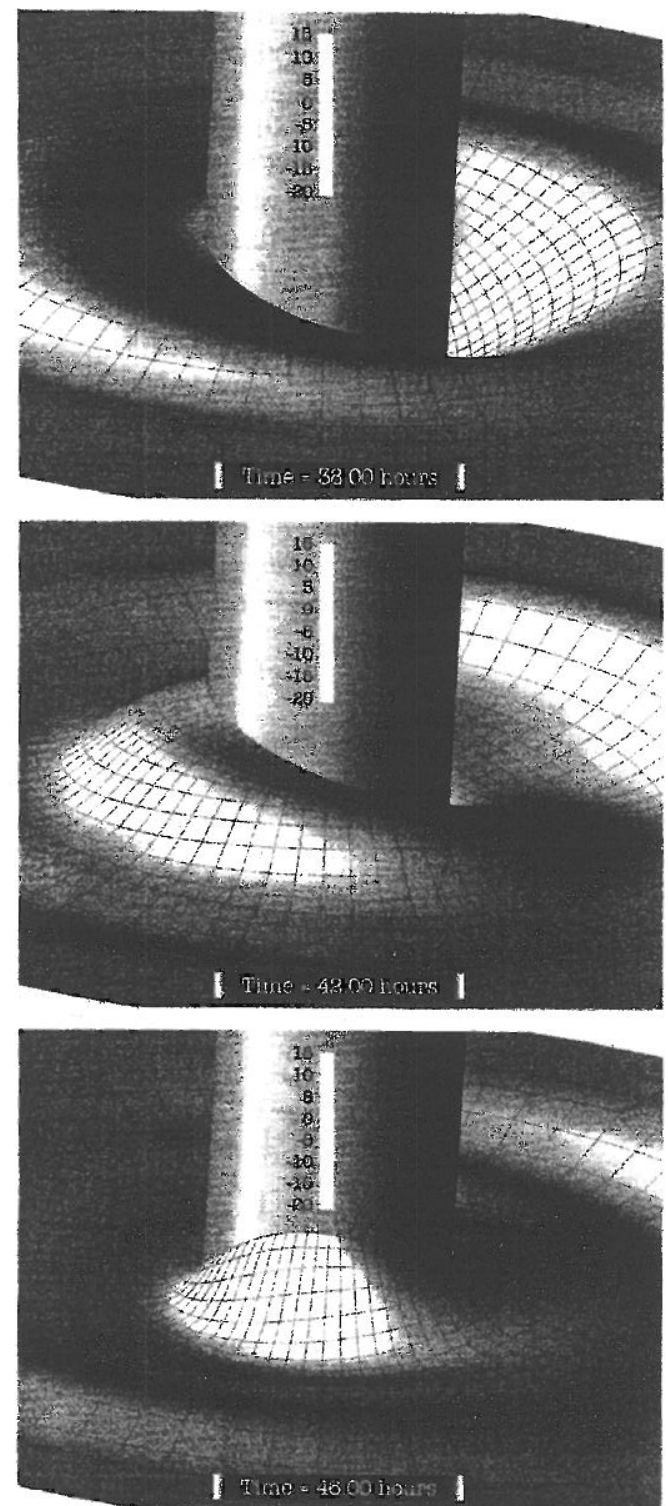

Fig. 10. Three-dimensional rendered examples of the predicted internal wave at Scott Reef assuming a flat ocean floor. 
sites A2 and B2 (bottom). The model wave extended offshore about one island diameter and propagated anti-clockwise along the island slopes (Fig. 10), there were no data to confirm this latter prediction. The predicted peak tidal currents were about $0.35 \mathrm{~m} \mathrm{~s}^{-1}$ and showed no island wake and eddy (Fig 11). At currents were about flow reversals across the pycnocline (not shown). In the model the system radiated energy as internal waves moving away from the island as free waves in the open ocean We had no moorings in the far field to verify this prediction. Thus, the 2-D model predicted that islands can generate free internal waves in the ocean, even though there was no flow separation and no island wake downstream of the island.

When the actual sea floor bathymetry was included in the model and a spring semi-diurnal tide of 4 was forced at the open boundaries, a number of new waves appeared in the model after about two days. The primary wave was qualitatively similar to that predicted for a flat bottom, namely a semi-diurnal internal tide with crests and troughs on opposite sides of the island, and the waves propagated anticlockwise around the island. The model internal wave increased with time to peak after 2 days at $40 \mathrm{~m}$ peak-to-trough. At that time the peak predicted currents were $0.55 \mathrm{~m} \mathrm{~s}^{-1}$. These predictions agree qualitatively with the observations, but the data

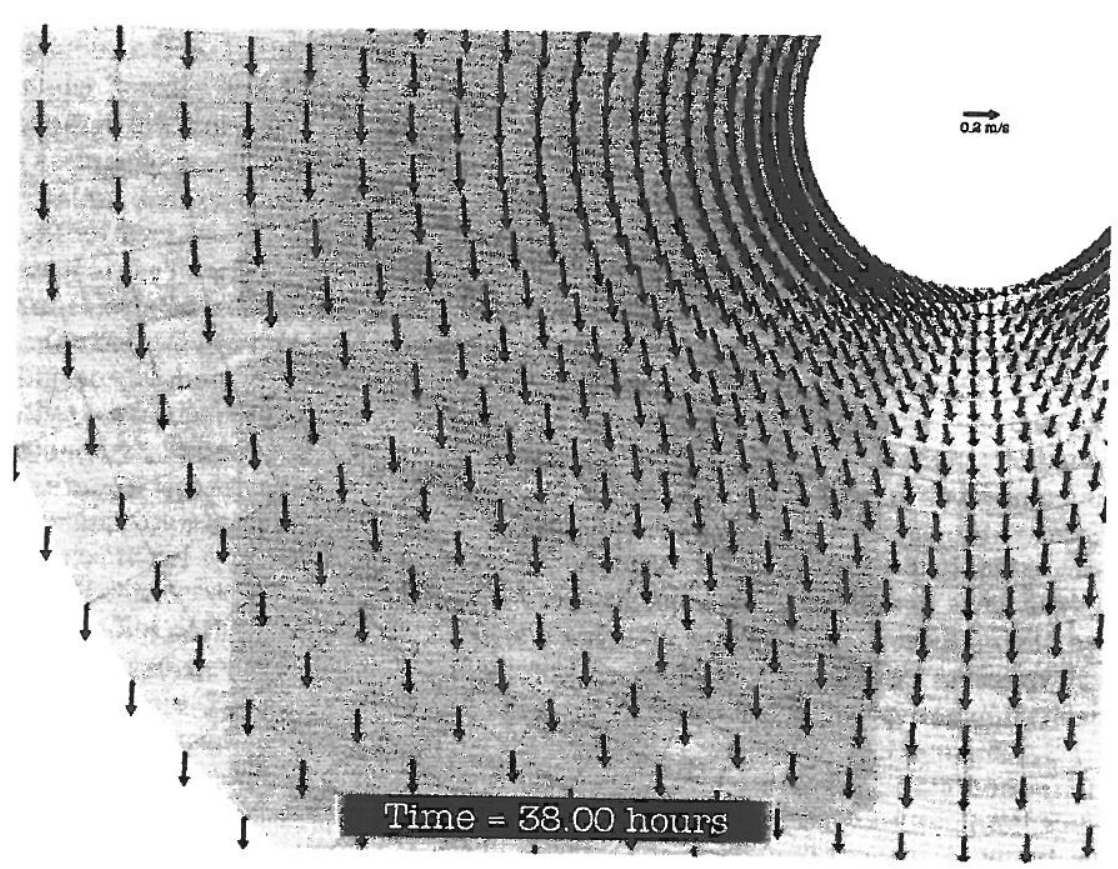

Fig. 11. Corresponding to Fig. 10, an example of the predicted velocity field in the bottom layer durin peak tidal currents shows no eddy in the lee of the island.

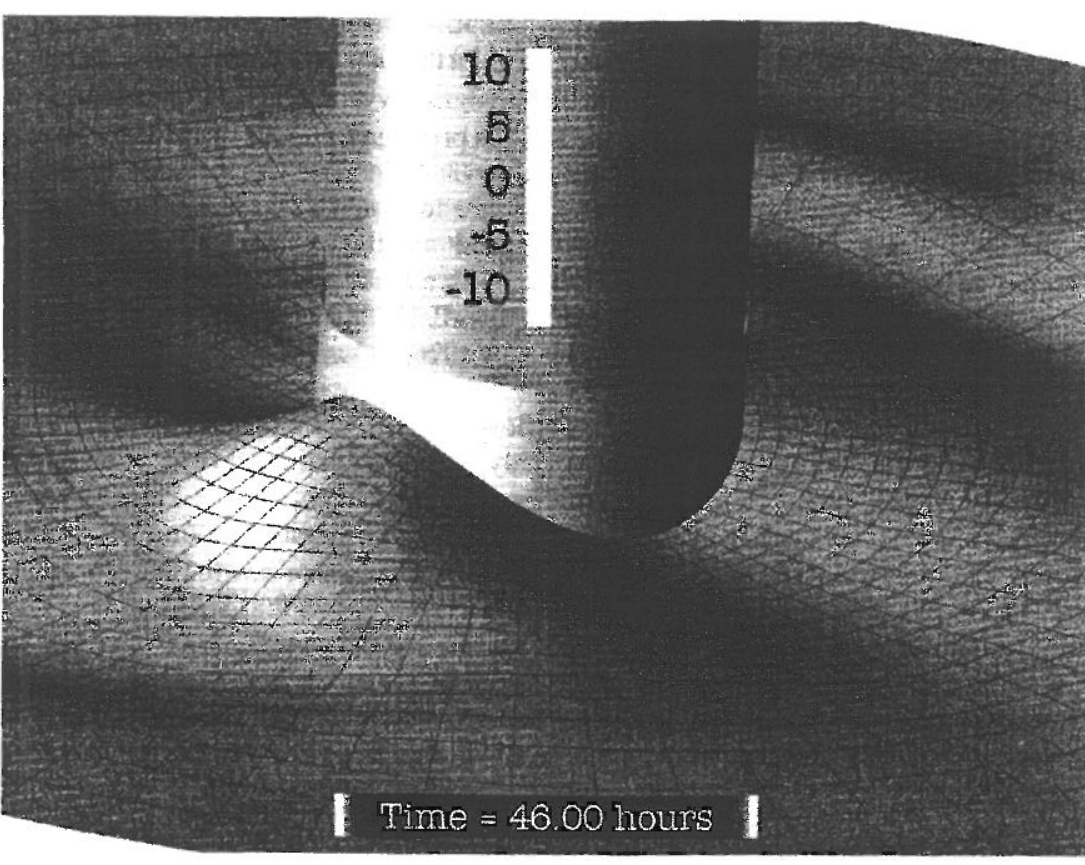

Fig. 12. Example of predicted high-frequency internal waves riding over the principal, semi-diurnal internal wave at Scott Reef; this simulation takes into account the actual bathymetry.

were too sparse for a detailed comparison between predictions and observations. After two days of simulations, the internal waves decreased to about $26 \mathrm{~m}$, much of the difference in the energy being used to sustain higher-frequency waves superimposed on the primary wave. These predicted high-frequency waves occurred on and off, without any clear patterns; they had no clear dominant frequencies, at times there were up to eight such waves during a tidal cycle, at other times only one or two. An example of a high-frequency wave riding over the primary wave is shown in Fig. 12. When such waves were present, they generate pycnocline fluctuations that were not correlated on either sides of the island, and these fluctuations occurred at higher frequencies than the semi-diurnal tidal one forcing the model. When this occurs the wave height does not decrease exponentially with distance from the island and a number of wave crests and troughs are visible away from the island (e.g. Fig. 12)

\section{Conclusions}

The formation of internal waves by unsteady tidal flows around islands is a mechanism apparently little studied in the past. Most studies of the generation of internal 
tides by the topography have focused on the bathymetry generating, reflecting and breaking the waves. The latter originated from further offshore usually as a result of shear. It has long been recognised that the topography can generate internal waves near the shelf edge, with the locally formed waves propagating both towards the ocean and towards the coast (Gould and McKee, 1973; Baines, 1982; Sherwin, 1988. Le Tareau and Maze, 1993). Very few studies have , Baines, 1982, Sherwin, 1988; Le waves by an island; these studies have focused mostly on the downstream of the island in an eddy or bubble in a stherm doming et et al., 1978; Gordon and Hughes, 1981; Hogg, et al., 1978; Wolanski, 1986; Heywood et al., 1990; Bowman et al., 1994; Dietrich et al., 1996). It was generally assumed that the isotherm doming was island trapped.

Our study suggests that in unsteady tidal flows the internal waves occur even in the absence of flow separation and without an eddy or bubble forming downstream of the island. It also suggests that the internal waves rotate around the islands, clockwise in the southern hemisphere, with maximum amplituds, antislopes, and radiate energy as free waves, in qualitative accorplitude along the island predictions of Longuet-Higgins (1969). In practice this suggests that Scott Reef may be an internal wave generator for the Indian Ocean in this area and may contribute to the oceanic variability even far from the island. The the observed low-frequency variability in the currents and temperature data, but not in the surface elevation data, may be due to the interactions between higher frequencies signals.

At very long periods ( $\geqslant 8$ days) the thermocline also fluctuated energetically (see the time series of the temperature at site B2 in Fig. 3; see also the temperature spectra of the temperature in Fig. 7). These fluctuations remain unexplained and may be due to large-scale fluctuations in the ocean. The wind may be the driving force for these fluctuations such as in Bermuda (Wunsch, 1972) but since the wind data were collected $200 \mathrm{~km}$ away a verification of this hypothesis at Scott Reef was data were

The model however is still very simple, in particular the model requires thosible. well-mixed top layer, the reef is circular with vertical walls. This is a roures that in the tion of Scott $\mathrm{Reef}$ which is tion of Scott Reef which is not circular and has a deep channel bisecting the island. The rugged topography may help facilitate flow separation much more than the model circular one allows. It may also help would explain the larger internal waves at site B than at site A.

Our data suggest that, contrary the present emphasis of studies of tidal flows past oceanic islands (e.g. Dietrich et al., 1996), the primary response of the tidal flow past deep oceanic islands is the formation not so much of an island of the tidal flow past huge, leaky internal waves. These waves rea have a major influence on the currents and temper peak to trough at Scott Reef and column. They can bring nutrients from below the pycnecline $200 \mathrm{~m}$ of the wate to within $40 \mathrm{~m}$ of to within $40 \mathrm{~m}$ of the surface where other small-scale flow processes in the spur-andgroove system of coral reefs may make them available to thess in the spur-andsurface (Wolanski and Delesalle, 1995). The in avallable to the coral reefs near the responsible for maintaining the coral reefs and fisheries. Fur are leaky, they also contribute to the variability of the ocean. A better understanding of island-generated internal waves is needed to help manage Scott Reef's rich fisheries, shared by Australia and Indonesia, and the eventual petroleum extraction activities.

\section{Acknowledgements}

This study was supported by the Australian Institute of Marine Science and the IBM International Foundation. The second author is a Research Associate with the Belgian National Fund for Scientific Research. It is a pleasure to thank Ray McAllister and Duncan Galloway.

\section{References}

Baines, P.G., 1982. On internal tide generation models. Deep Sea Research 29, 307-338.

Baines, P.G., 1983. Tidal motions in submarine canyons- a laboratory experiment. Journal of Physica Oceanography $13,310-328$.

Bowman, M.J., Stansfield, K.L., Fauria, S.J., Wilson, T.C., 1994. Coastal ocean circulation near Barbados, West Indies, Spring 1990 and 1991. Journal of Geophysical Research 99 (C8), 16,131-16,142.

De Young, B., Pond, S., 1987. The internal tide and resonance in Indian Arm, British Columbia. Journal of Geophysical Research 92 (C5) 5191-5207.

Dietrich, D.E., Bowman, M.J., Lin, C.A., Mestas-Nunez, A., 1996. Numerical studies of small island wakes. Geophysical and Astrophysical Fluid Dynamics 83, 195-231.

Di Sarra, A., Pace, A., Salusti, E., 1987. Long internal waves and columnar disturbances in the Strait of Messina. Journal of Geophysical Research 92 (C6), 6495-6500.

Garrigues, L., Deleersnijder, E., Rancher, J., 1993. Modelisation bi-dimensionalle a deux couches de circulation autour d'iles. Application aux atolls de Fangataufa et Mururoa. Service Mixte de Securite Radiologique, Monthery, France, 85 pp.

Gordon, H.B., Hughes, R.L., 1981. A study of rotating non-linear flow around an island. Journal of Physical Oceanography 11, 1011-1014.

Gould, W.J., Mckee, W.D., 1973. Vertical structure of semi-diurnal tidal currents in the Bay of Biscay. Nature 244, 88-91.

Heywood, K.J., Barton, E.D., Simpson, J.H., 1990. The effects of flow disturbance by an oceanic island Journal of Marine Research 48, 55-73.

Hogg, N.G., 1972. Steady flow past an island with application to Bermuda. Geophysical Fluid Dynamics, 4, $55-81$.

Hogg, N.G., Katz, E., Sanford, T.B., 1978. Eddies, islands and mixing. Journal of Geophysical Research, 83, 2921-2938.

Holloway, P.E., 1996. A numerical model of internal tides with application to Australian North West shelf Journal of Physical Oceanography 26, 21-37.

Holloway, P.E., Barnes, B., 1998. A numerical investigation into the bottom boundary layer flow and vertical structure on internal waves on a continental slope. Continental Shelf Reseach 18, 31-65.

Huthnance, J.M., 1989. Internal tides and waves near the continental shelf edge. Geophysical Fluid Dynamics 48, 81-106.

Lamb, K.G., 1994. Numerical experiments of internal wave generation by strong tidal flow across a finite amplitude bank edge. Journal of Geophysical Research 99, 843-864.

Le Tareau, J.Y., Maze, R., 1993. Storm effects on the baroclinic tidal field in the Bay of Biscay. Journal of Marine Systems 4, 327-347.

Longuet-Higgins, M.S., 1969. On the trapping of long-period waves around islands. Journal of Fluid Mechanics 37, 773-784. 
Maxworthy T., 1979. A note on the internal solitary waves produced by tidal flow over a three-dimensional ridge. Journal of Geophysical Research, 84, 338-346.

Morozov, E.G., Vlasenko, V.I., 1996. Extreme internal waves near the Mascarene ridge. Journal of Marine Systems $9,203-210$

Rougerie, F., Fagerstorm, J.A., Andire, C., 1992. Geothermal endo-upwelling: a solution to the reef nutrient paradox? Continental Shelf Research 12, 785-798.

Schwiderski E.W 1979. Globlocentid charts and maps. Naval Surface Weapons Center, Silver Springs, MD, NSWC-TR-79-414.

Sherwin, T.J., 1988. Analysis of internal tides observed on the Malin shelf, North of Ireland. Journal of Porth of Ireland. Journal of Physical Oceanography 18, 1035-1050.

in M., Peterson, W.T., (Eds), Tidal mixing and plankton dynamic Springer, Berlin, vol. 17, pp. 41-76. Simpson, J.H., Tett, P.B., Argotte-Espinoza, M.L., Edwards, M., Jones, K.J., Savidge, G., 1982. Mixing an phytoplankton growth around an island in a stratified sea. Continental Shelf Research 1, 15-31. Wilmont, A.J., Edwards, P.D., 1987. A numerical model for the generation of tidally forced nonlinear internal waves over a topography. Continental Shelf Research 5, 457-484.

Wolanski, E., 1986. Island wakes and internal tides in stratified shelf waters. Annales Geophysicae 4 $425-440$

Wolanski, E., Drew, E., Abel, K., O'brien, J.J., 1988. Tidal jets, nutrient upwelling, and their influence on the productivity of the lag Halimeda in the Ribbon Reefs, Great Barrier Reef, Australia. Estuarine, Coastal and Shelf Science, 26, 169-201.

Wolanski, E., Delesalle, B., 1995. Upwelling by internal waves, Tahiti, French Polynesia. Continental Shelf Research 15, 357-368.

Wunsch, C., 1972. The spectrum of two years to two minutes of temperature fluctuations in the main thermocline at Bermuda. Deep-Sea Research 19, 577-593. 